\title{
Spatial planning solutions for the housing redevelopment project as an element of improved housing ecology
}

\author{
Ekaterina Vasileva ${ }^{1, *}$, Oleg Tsvetkov ${ }^{1}$, and Lyubov Manukhina ${ }^{2}$ \\ ${ }^{1}$ Peter the Great St.Petersburg Polytechnic University, 195251, Polytechnicheskaya str., 29, \\ St.Petersburg, Russia \\ ${ }^{2}$ Moscow State University of Civil Engineering, 26 Yaroslavskoe shosse, Moscow, 129337, Russia
}

\begin{abstract}
In this article, in the context of home ecology, authors rise the problem of the interpretation of such concepts as «reequipment» and «redevelopment» of residential premises. Which are found in the texts of the Housing Code of the Russian Federation and the Decree of the State Building N170 of 27 September 2003. The authors propose that, along with the well-known components of the ecology of the dwelling, positive changes in the design of the space planning solutions should be considered as one of the criteria for improving the evaluation. In practice, participants in the projects while improving the environment in the homes, face the proliferation of these terms, which are misleading and require further specifications. The article contains the results of real housing redevelopment projects implemented in 2019-2020 in the Kalininsky district of SaintPetersburg. In addition, the main preferences of the owners of the apartment buildings were taken into consideration. Until recently all of these activities were carried out by the owner, but at the time of the research all works were carried out by licensed specialists. It is suggested that such projects will continue to evolve, however, this process will depend on the introduction of new environmentally friendly building materials and technologies. Moreover, when household appliances will take a bigger share on the consumer market, there will be the improvement of the quality of the indoor environment and it will diversify the capabilities of the owners.
\end{abstract}

\section{Introduction}

With the adoption of the Housing Code of the Russian Federation, not only such concepts as «redevelopment» and « reequipment » have been consolidated at the legislative level, but the mechanism of the legal regulation of the reorganization and redevelopment of the living quarters has also changed.

It follows from article 25, paragraph 2, of this document that the redevelopment of the living quarters is a reconfiguration of the accommodation, which requires a change in the

\footnotetext{
*Corresponding author: katrinvasileva1997@icloud.com
} 
technical passport of the living quarters. This definition not only fails to explain the term but may also mislead the owner.

However, from the very beginning paragraph 1.7.1 of the Basic Provisions of the Decree of the State Building of the Russian Federation of 27 September 2003 N 170 "On the approval of the Rules and Standards for the Technical Operation of the Fund" strictly regulates what is included in the redevelopment. The redevelopment of accommodation may include:

- Removal and disassembly of partitions;

- the transfer and design of door openings,

- Disaggregation or consolidation of multi-unit flats;

- Installation of additional kitchens and bathrooms;

- Expansion of living space through support facilities;

- Eliminating dark kitchens and their entrances through living quarters,

- Arrangement or alteration of existing tamburas.

The term «reequipment» is introduced consecutively in the Housing Code. According to article 25, paragraph 1 , the reequipment of an apartment building is the installation, replacement, or relocation of engineering networks, sanitation, electrical or other equipment, requiring changes to the technical passport of the premises in the apartment building [1].

The meaning of this term is more precisely understood in the Decree of the State Building of the Russian Federation. It is important to highlight, however, that the term «conversion» is used instead of « reequipment» in the text of this Decree. This also raises additional questions to owners. According to paragraph 1.7.1 of the Basic Provisions of the Decree of the State Building of the Russian Federation, reequipment of residential premises may include:

- Installation of domestic electric stoves to replace gas stoves or kitchen stoves;

- Transfer of heating appliances and gas appliances,

- Re-installing and refurbishing existing toilets, bathrooms,

- Construction of new or replacement of existing supply and discharge pipes, electrical networks, and equipment for the installation of showers, Jacuzzis, high-capacity washing machines, and other new-generation plumbing and plumbing appliances [2].

\section{Materials and methods}

In this study, an analysis of the renovation projects for 2019-2020 in the Kalininsky district of Saint-Petersburg was made. Twenty-three objects with different types of redevelopment were analyzed. The procedure of changing the functional assignment of premises in a single apartment of a multi-story, multi-story residential building begins with an engineering survey $[3,4]$. A separate observation is made of the fact that in all cases the redevelopment of the premises was carried out in conjunction with the reconfiguration. Thus, the question arises whether it is necessary to introduce such a concept as «reequipment».

The statistical material that were collected during the research revealed changes in the area and the main patterns in the redevelopment process.

The obtained data are reflected in the comparison diagrams of the residential and auxiliary areas before and after the work related to the redevelopment of premises (See Figures 1 and 2). 


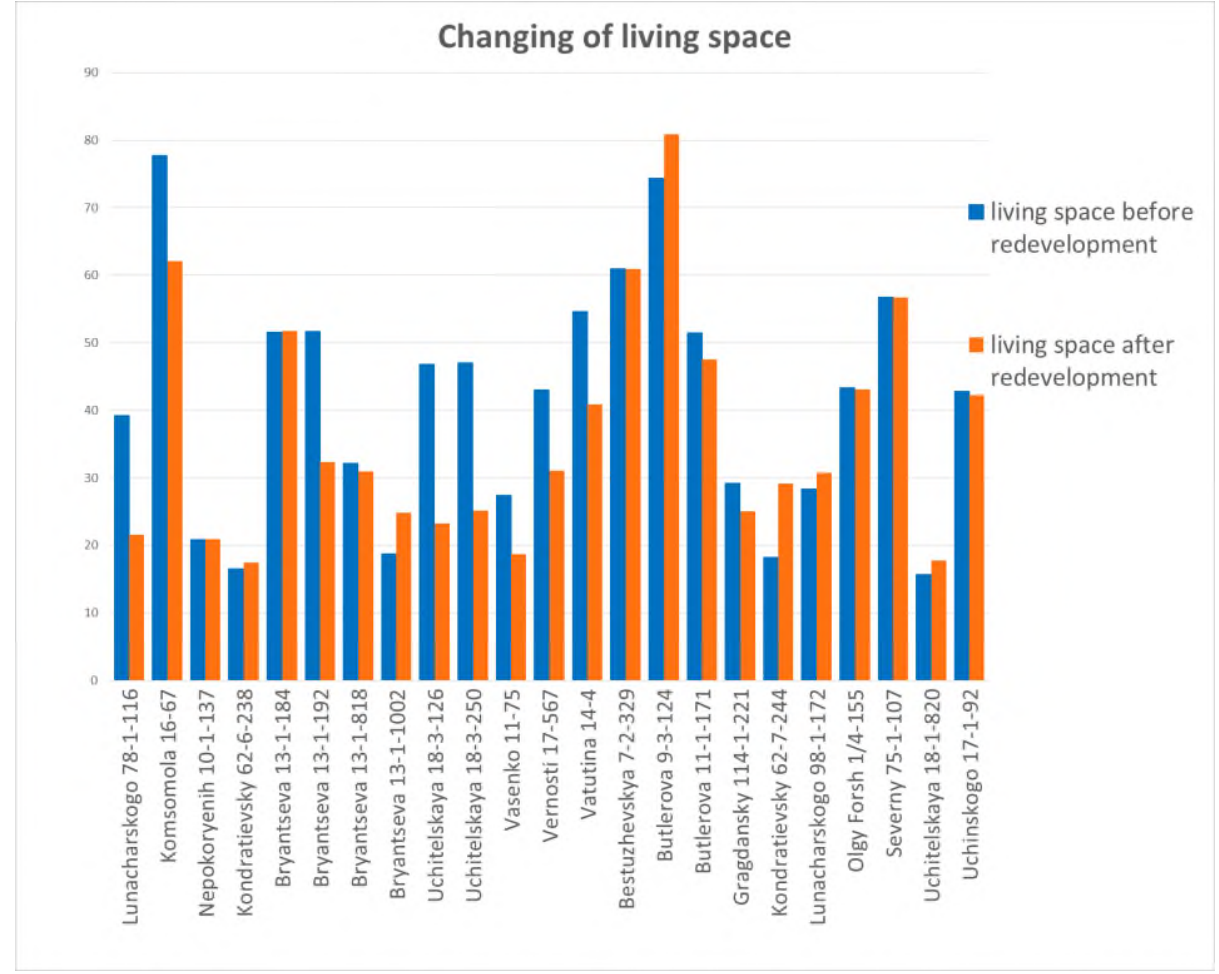

Fig. 1. Analysis of changes in living space.

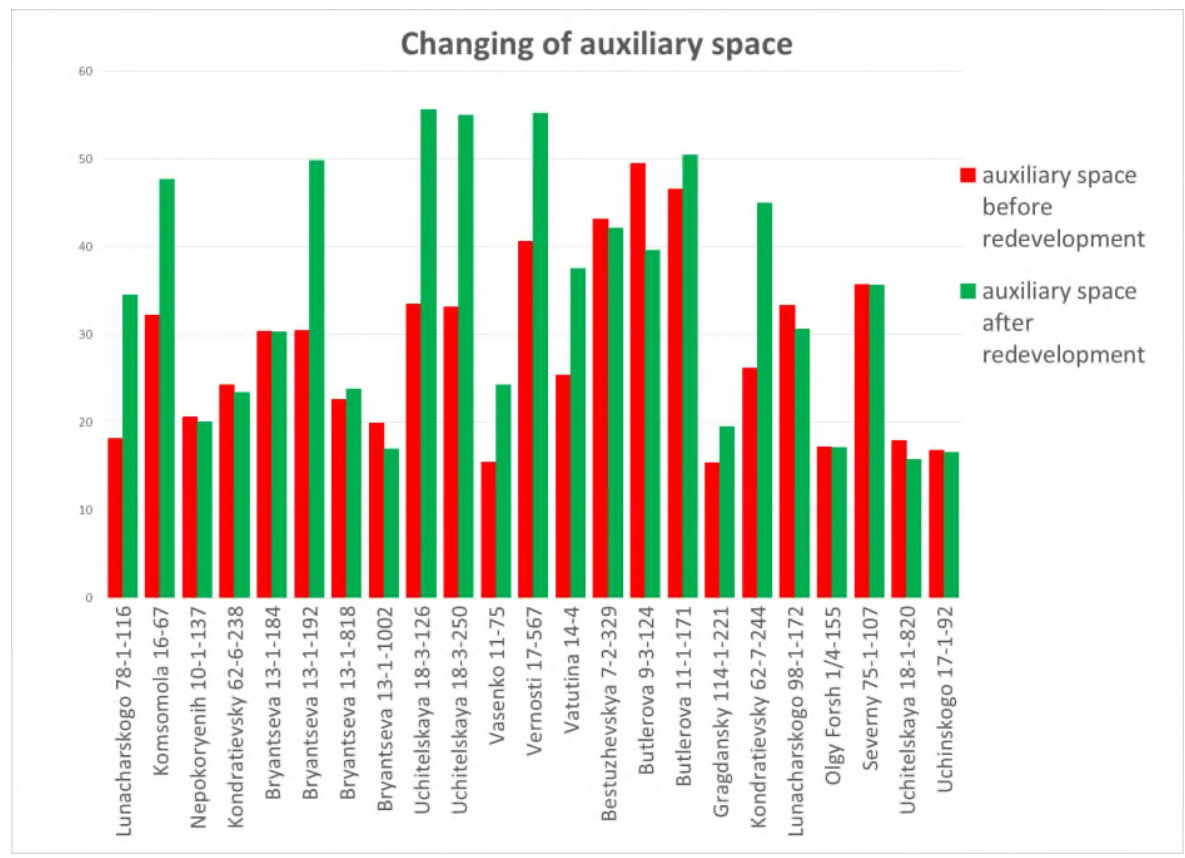

Fig. 2. Analysis of changes in auxiliary space. 
The data obtained were quite indicative of the preferences that prevail among the majority of the inhabitants of the Saint-Petersburg, who planned and made changes in their housing environment.

These days, there is the increase of dwellings in the auxiliary premises by reduction of the living space of flats owned by citizens. This shows that there has been a fundamental change in the mindset of the citizens towards the improvement of living conditions. If only a few years ago the main motivation for the redevelopment was to increase the area suitable for habitation. Today people give preference to boudoir, wardrobe, kitchen-parlor, halls, etc. [5-7].

\section{Results}

In the analysis of the data obtained within the analysis, it is possible to distinguish several types of volumetric-planning solutions of realized projects of redevelopment of apartments in 2019-2020.

\subsection{Combining kitchen with living room}

This type of redevelopment is carried out through the partial or complete removal of the wall between the kitchen and the living room. Popular options are kitchen-parlors in two or threeroom apartments where the owner wishes to have a single kitchen area and living room [8]. This type of redevelopment is an excellent opportunity for those who like the spacious area and want to organize a common space to communicate with their family and friends at a common table by placing a sofa, a bar, or a large dining table nearby. The presence of a television panel and an electric fireplace with the illusion of open fire and the specific sound effects of burning firewood is a necessary attribute of the long-term arrangement of the premises.

However, it should be noted that this type of redevelopment has several nuances [9]. First, it is prohibited to place the kitchen above the living room. Second, if the kitchen is gasified, folding doors or roller doors must be installed. Thirdly, the kitchen could not be combined with the living room, and finally, the bearing wall could not be dismantled, but only the embrasure with strengthening could be created.

The entire kitchen area is enlarged at the expense of the living rooms and doors«harmonics» were installed for fire safety.

\subsection{Integration and organization of additional sanitation facilities}

In this type of redevelopment, the bathroom and toilet are often combined to provide a spacious room and installing a Jacuzzi, bidet, washing machine (drying machine), additional shower cabin, or modern units that resemble a bath sauna or setting-up of the hammam and so on [10]. When the toilet is combined with the bathroom, the partition is often removed, or it is made of glass or sliding made of modern materials and standard structures, which are customized by the domestic and foreign industry.

However, here again there are several limitations. It should be remembered that you cannot place a bathroom above a kitchen or a living room. The bathroom or toilet can only be enlarged by auxiliary rooms such as a storeroom, corridor, or wardrobe.

As a result of the combination of the bathroom, the previously deprived amenities of the premises become more practical and spacious. In addition by redistributing the area of the corridor in a downward direction, the bathroom becomes comfortable. 
As a result of the redevelopment, the toilet room is usually combined with the bathroom and the increase of its area is achieved by the corridor count. It should be noted that very often the combination of the toilet with the bathroom implies the reequipment of the new room.

The next type of redevelopment of the bathrooms is to equip additional one. If the apartment originally has two combined bathrooms, then, after the redevelopment, due to one of them, the kitchen area increases, so that the kitchen-living room is organized and a new bathroom is equipped $[11,12]$.

\subsection{Dismantling of window sill}

This type of redevelopment involves dismantling the window sill to install double doors or windows into the floor.

The installation of windows or double doors makes the space seem larger and improves indoor insolation. However, such redevelopment could only be done if the wall is not a bearing. If the wall between the loggia and the room is a load-bearing wall, it is strictly forbidden to dismantle it, as this would be a deterioration of the general household property. To get a permission for such a reorganization, it is it is necessary to collect the consent of all the owners of the apartment building [13].

\subsection{Arrangements for wardrobe and storage systems}

The device of dressing rooms, storerooms, laundry rooms, and cabinets significantly improves living conditions and saves the space of living rooms due to its functionality.

\section{Discussion}

Modern society is aspired to minimalism and the organization of extensions for its own needs, thus making it possible to store many things in one place. This type of redevelopment is not limited to any regulations, but people use both auxiliary and living space to create wardrobes. There are quite a few examples of redevelopment where parts of the living room are reorganized by the wardrobe. Often, only fixed shelves, hangers and glass partitions are required for the installation of a closet in the living room [14, 15].

Based on the data obtained, it can be concluded that today the citizens of Saint-Petersburg are striving for convenience and minimism in the design and implementation of the redevelopment of their premises in Saint-Petersburg. The society begins to give up small kitchens and bathrooms in favour of kitchen-parlours with panoramic windows and combined bathrooms and wardrobes.

What is more, it is also worth noting that, since 2013, instead of a technical passport, the document disclosing information on a real estate property is a extract from the Single State Real Property Register. It is a reliable source of information in the territory of the Russian Federation.

\section{References}

1. K. V.Tikhonova, O. A. Stadnikova. Organizational and economic specifics of entering information in USRRE as a result of restructuring and redevelopment areas, Economy and ecology of territorial formations 3, 1, 82-90 (2019) https://doi.org/10.23947/24131474-2019-3-1-82-90 
2. A.M. Rybkina, V.F. Kovyazin, D.A. Golovatskaya, Concept and classification of transformations of non-residential premises for the purposes of the state cadastre accounting, Moscow Econ. J. 7 (2019) DOI 10.24411/2413-046X-2019-17043

3. T. Simankina, M. Romanovich, O. Tsvetkov, Wavelet analysis function of changing average work amounts in monolithic construction, MATEC Web of Conferences C.01054 (2016)

4. P. Iatsinevich, N. Braila, M. Korenevskaya, S. Erzakov, T. Simankina, Reconstruction of industrial building with nonstandard space-planning decisions, IOP Conference Series: Materials Science and Engineering, Construction - The Formation of Living Environment 21, 022045 (2018)

5. K. Pykhtin, T. Simankina, K. Karmokova and A. Zonova, Determination of the optimal proportions of public and private funds in project budget management, IOP Conf. Series: Earth and Env. Sci. 90, 012208 (2017) doi:10.1088/1755-1315/90/1/012208

6. T. Simankina, O. Popova, Neural network application for scheduling of building constraction repair, Appl. Mech. and Mater . 584-586, 1944-1950 (2014)

7. T. Simankina, N. Braila, Functional performance of piece of property with account for its level of environmental security, Appl. Mech. and Mater. 584-586, 723-727 (2014)

8. T. Simankina, J. Ćetković, N. Verstina and E. Evseev, Influence of the economy crisis on project cost management, IOP Conf. Series: Earth and Environmental Science 90 012209 (2017) doi :10.1088/1755-1315/90/1/012209

9. O. Tsvetkov, T. Simankina, K. Karmokova, Video-ecological coefficient of real estate objects, E3S Web of Conferences 05028 (2019)

10. A.V. Bobkov, O.Yu. Czvetkov, Russia In The Asian - Pacific Region: The Scientific And Technical Policy's Activization Necessity, Eur. J. of Nat. Hist. 2, 34-35 (2010)

11. T. Simankina, O. Sergeenkova. Resourse optimization of construction on a basis of the frontal and rhythmical stream, Appl. Mech. and Mater. 725-726, 984-989 (2015)

12. O.N. Popova, E.A. Bogachyova. Analysis of the methods for assessing socio-economic development level of urban Areas, AIP Conf. Proc. 1800 (050015) (2017) doi : $10.1063 / 1.4973075$

13. O. Tsvetkov, E. Vasileva, K. Kulakov, Features of cadastral registration of real estate objects using 3D technologies, E3S Web of Conferences 217, 02007 (2020) DOI: 10.1051/e3sconf/202021702007

14. L. Talipova, E. Kosyakov, M. Romanovich, M. Lunyakov, Change of the functional purpose of the object through urbanistic analysis, MATEC Web Conf. 170, 02011 (2018) DOI:https://doi.org/10.1051/matecconf/201817002011

15. M.V. Perkova, O.M. Donchenko, Effective architectural-planning and constructive decisions of multi-storey civil buildings, Bulletin of BSTU named after V.G. Shukhova 1 (2017) DOI: $10.12737 / 24094$ 